\title{
How many days do researchers have to wait for their papers to be published?
}

\section{Maaya OOUE Tokai University maaya_oue@yahoo.co.jp}

\section{Background}

This study aims to calculate how many days we have to spend from submitting manuscript to be accepted by journal editors, and consider what factors influence on it.

Now in Japan, not a few young researchers mind when their research papers will be published. That's because almost all graduate schools need doctor course students to write some academic peer-reviewed journal articles to confer Ph.D on them. Also, the number of papers a researcher wrote is of critical importance when he/she search job in academia. To build their career, researchers' knowing the length of the time to publish a paper is useful.

\section{Methods}

\section{Subject journals}

1. The Japanese Journal of Japanese Educational Psychology

2. Cognitive Studies

3. The Japanese Journal of Personality

Top3 IF

journals in psychology (Kato et al., 2015)

4. Psychological Bulletin .one of the world's highest IF psychological journals

Data (from 2008 to 2017)

- the date of receive and acceptance of manuscripts (only original articles)

- the numbers of original articles

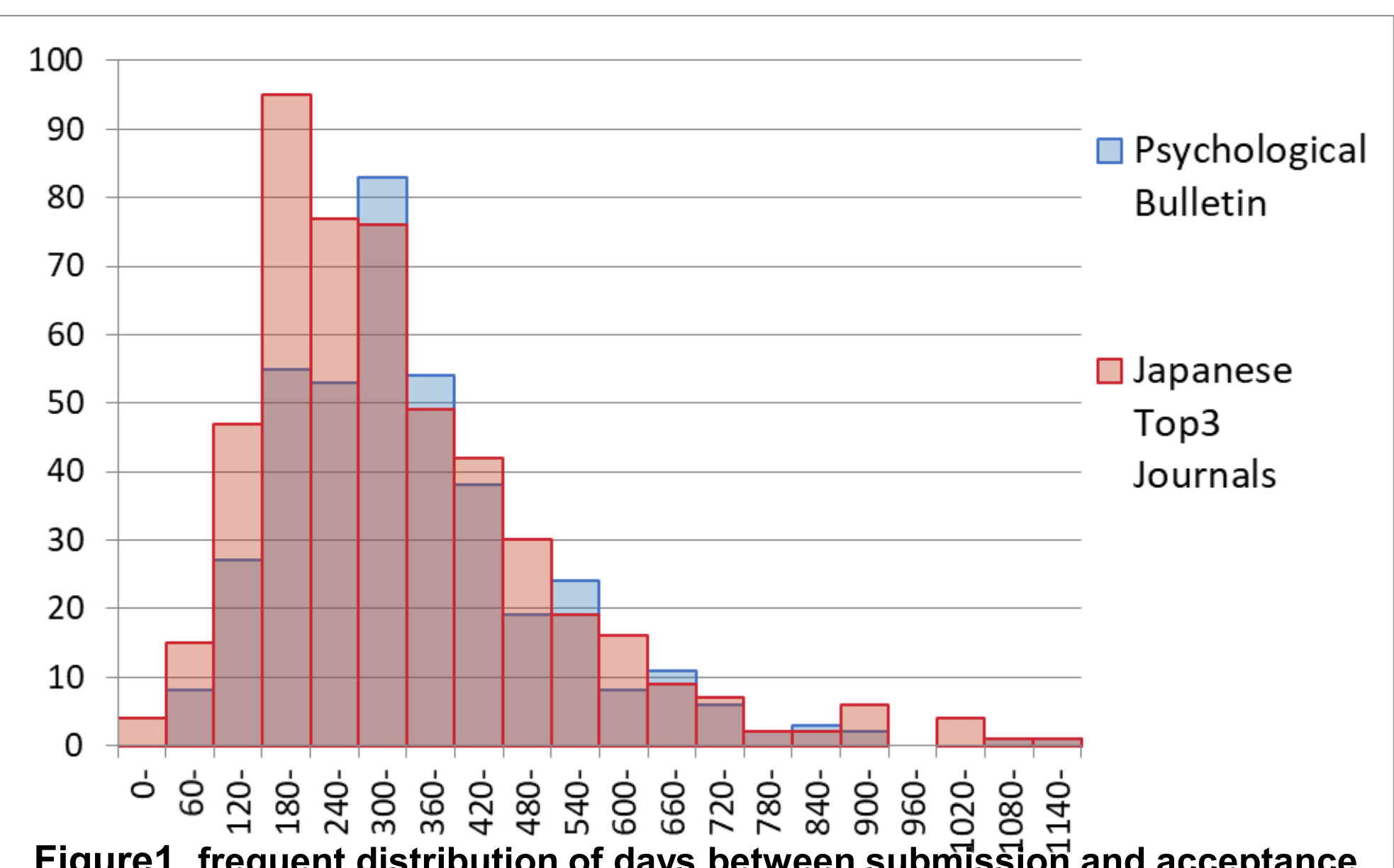

Table1 descriptive statistics values of four journals' days

\begin{tabular}{ccccc}
\hline & $\begin{array}{c}\text { Cognitive } \\
\text { Studies }\end{array}$ & $\begin{array}{l}\text { the Japanese } \\
\text { Journal of } \\
\text { Personality }\end{array}$ & $\begin{array}{l}\text { the Japanese } \\
\text { Journal of } \\
\text { Educational } \\
\text { Psychology }\end{array}$ & $\begin{array}{l}\text { Psychological } \\
\text { Bulletin }\end{array}$ \\
\hline$N$ & 91 & 124 & 288 & 396 \\
\hline Mean & 295.2 & 326.0 & 377.5 & 366.3 \\
\hline Median & 241 & 296 & 332 & 335.5 \\
\hline$S D$ & 181.8 & 178.4 & 194.5 & 170.2 \\
\hline $\begin{array}{c}\text { skewness } \\
\text { (歪度) }\end{array}$ & 1.357 & 1.440 & 1.565 & 1.388 \\
\hline $\begin{array}{c}\text { kurtosis } \\
\text { (尖度) }\end{array}$ & 2.077 & 2.908 & 3.234 & 3.660 \\
\hline Min & 37 & 27 & 50 & 67 \\
\hline Max & 1022 & 1042 & 1242 & 1329 \\
\hline
\end{tabular}

\section{Findings}

Japanese journals averaged 350 days ( $n$

$=503, S D=191$ ) and the Psychological Bulletin took 366 days $(n=396, S D=$ 170) on average from the date of receipt to the date of acceptance in the decade for which the data were studied. There was no significant difference between the Japanese journals and the international publication.

The combined data for all four journals were used to correlate the annual average time lapse with the number of papers published in that year $(r=.524, p$ $=.0005$ ).

Kato, T. et al., (2015). Impact Factors of twenty seven psychological journals from 2000 to 2010. Kato's Lab Paper, 2015-001. Sakamoto, S., \& Oohira., H. (Eds.) (2013). A training hall for writing psychological papers in English. Sekaishisosha-Kyogakusha Co. Ltd, Kyoto.

\section{Discussion}

Researchers must wait a year for their papers to be published in the selected journals. The results of this investigation did not conform to Sakamoto's assertion (2013) that English Journal articles tend to be reviewed faster than Japanese.

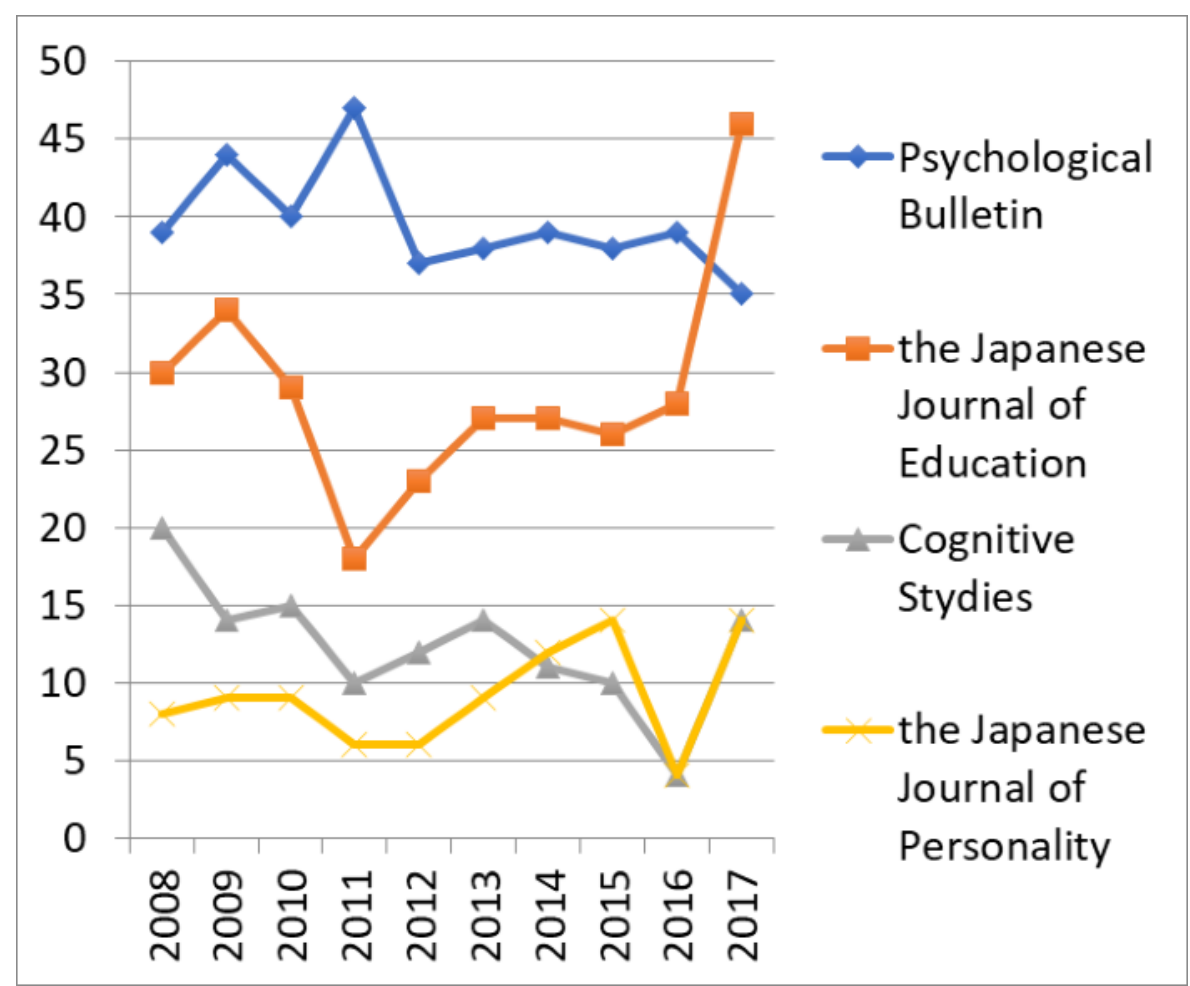

Appendix 1 Transitive graph of each journals' numbers of original articles
This investigation did not consider acceptance rates. Further studies should scrutinize the acceptance rates, collect data over a larger span of time, and explore other psychological journals.

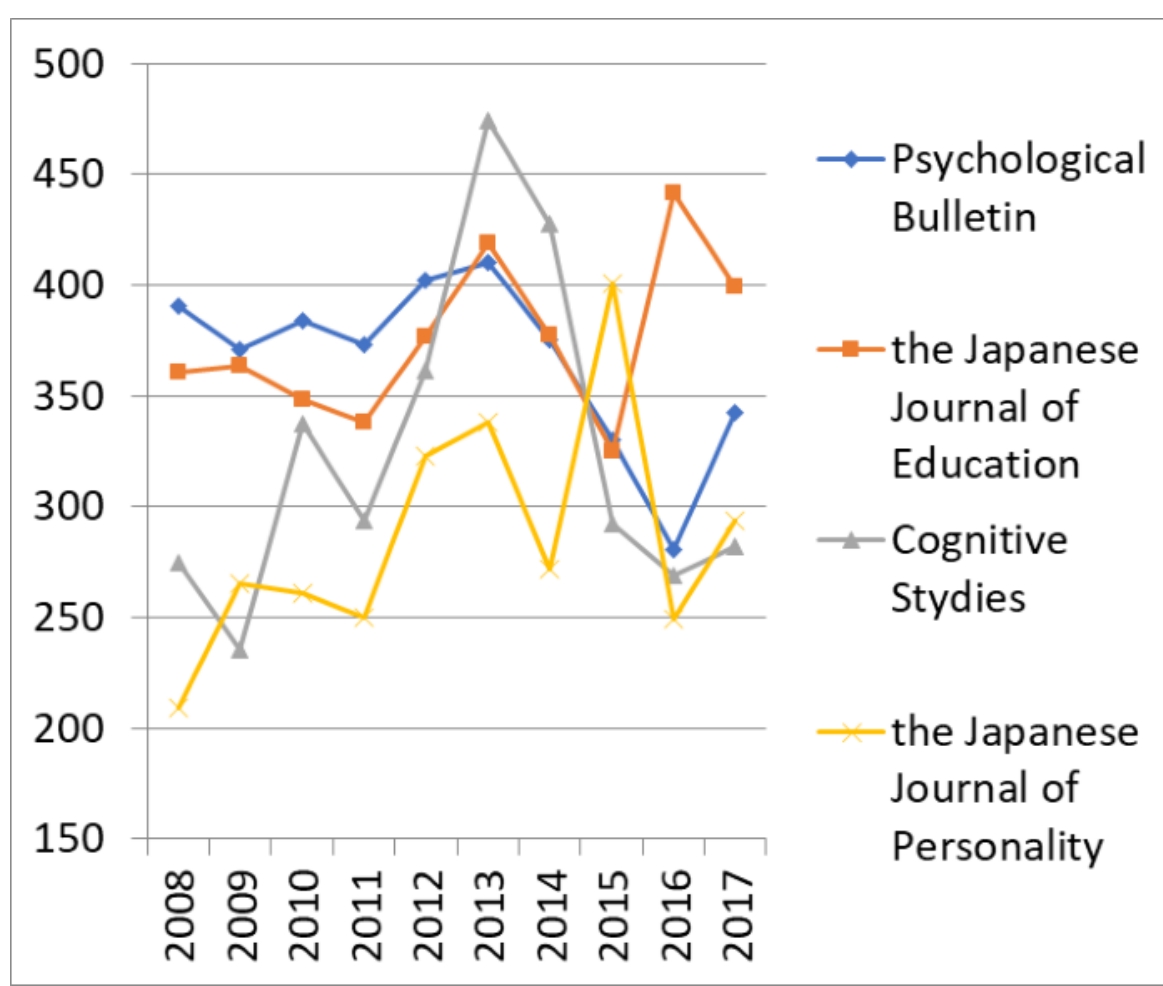

Appendix 2 Transitive graph of each journals' duration 